\title{
LA COLABORACIÓN DE LAS VÍCTIMAS EN LA PERSECUCIÓN PENAL DE LA VIOLENCIA DE GÉNERO EN ESPAÑA
}

Fernando Vázquez- Portomeñe Seijas*

\begin{abstract}
Resumen: El objetivo principal de este trabajo es analizar la actitud de las víctimas de violencia de género en España a la hora de interponer la correspondiente denuncia y de testificar en el juicio oral. Para su elaboración se ha analizado un total de 580 expedientes de la Fiscalía de Área de Santiago de Compostela, relativos a delitos de violencia contra la mujer, correspondientes a los años 2005 a 2012. Nuestro estudio permite afirmar que, aunque cada víctima representa un caso único, su actitud a la hora de denunciar el maltrato se halla mediatizada por determinadas circunstancias relativas a la forma de convivencia y a la titularidad de la vivienda en que convive con el agresor. También se concluye que el hecho de que la víctima se negara a declarar influye, como dato estadísticamente significativo, en la decisión final del órgano judicial de absolver al acusado.
\end{abstract}

Palabras clave: Violencia contra la mujer, Víctimas, Denuncia, Testimonio.

Doctor en Derecho, Profesor Titular de Derecho Penal, Universidad de Santiago de Compostela (España); Santiago de Compostela, España.Correo-e: fernando.portomene@usc.es. Fecha de recepción: 6 de diciembre de 2016. Fecha de aceptación: 15 de enero de 2018. Para citar el artículo: FERNANDO VÁSQUEZ-PoRTOMEÑE SEIJAS, "La colaboración de las víctimas en la persecución penal de la violencia de género en España”, en Revista Derecho Penal y Criminología, Vol. 38, n. . 105, julio-diciembre de 2017, Bogotá, Universidad Externado de Colombia, pp. 101-125.

DOI: https://doi.org/10.18601/ 01210483.v38n105.05 


\title{
VICTIMS COOPERATION IN THE PROSECUTION OF GENDERED VIOLENCE IN SPAIN
}

\begin{abstract}
The aim of this work is to present some questions relating the penal prosecution of the crimes of violence against women, and specifically with regard to the attitude of the victims when reporting the aggressions and to their participation as witnesses at trial. A total of 580 files, classified as IPV from the prosecutor office of Santiago de Compostela, were analysed with the statistical package SPSS). The period under study extended from January 2005 to December 2012. We found that factors relating the forms of cohabitation and the ownership of the house generate distortions, both in terms of content and expression of victim's testimony, and that their refusal to testify has a determining influence on the decision to acquit the accused.
\end{abstract}

Keywords: Violence against Women, Victims, Report, Testimony.

\section{CONSIDERACIONES PREVIAS}

Como es sabido, la interposición de denuncia reviste una extraordinaria importancia en los delitos de violencia contra la mujer, al condicionar su visibilidad y persecución. De hecho, junto con la conveniencia de mejorar los instrumentos para prevenir e identificar la violencia y la necesidad de reajustar los criterios de intervención que pueden conllevar un riesgo de revictimización, uno de los elementos centrales en las estrategias internacionales en esta materia es la implicación de las víctimas desde el comienzo mismo del proceso. Idéntica relevancia debe atribuírseles a sus declaraciones testificales -con frecuencia, la única prueba directa con que se contará en el proceso, si bien sujetas por la jurisprudencia a rígidos criterios de validación- y, en consecuencia, a los presupuestos y límites de la dispensa del deber de declarar, que muchos operadores judiciales asocian, paradójicamente, al fracaso del sistema de protección penal de las mujeres ${ }^{1}$. El objetivo de este estudio es determinar qué factores y variables (sociodemográficos y criminológicos) se asocian a los comportamientos procesales que acaban de mencionarse, para facilitar ese conocimiento a los operadores jurídicos y evitar, de ese modo, una posible victimización secundaria ${ }^{2}$

1 Vid. Erice Martínez, Esther, "La retractación de la denunciante en la aplicación de la Ley Orgánica de medidas de protección integral contra la violencia de género”, Estudios de Derecho Judicial, n. ${ }^{\circ}$ 139, Madrid, Consejo General del Poder Judicial, 2007, pp. 155 y ss.

2 Vid. Cubells, Jenny et al. "El ejercicio profesional en el abordaje de la violencia de género en el ámbito jurídico-penal: un análisis psicosocial”, Anales de Psicología, vol. 26, n. ${ }^{\circ}$ 2, julio de 2010, Murcia, Universidad de Murcia, 2010, p. 376. 


\section{LA VÍCTIMA-DENUNCIANTE}

A pesar de que la Ley Orgánica 1/2004, de Medidas de Protección Integral contra la Violencia de Género (en adelante LVG), condiciona el acceso a los recursos económicos, sociales y laborales previstos para las mujeres maltratadas, justamente, a la interposición de denuncia, sabemos que un número significativo de víctimas resuelve no hacerlo. De hecho, una de las ideas que se ha venido poniendo en solfa a lo largo de los últimos años es la de que la sociedad española, en general, y la mujer en particular, es cada día más consciente de la necesidad de denunciar estos delitos. Ello se pone de manifiesto en los datos aportados en la última macroencuesta realizada por la Delegación del Gobierno para la Violencia de Género, en 2015, en la que se recoge el dato de que, de las mujeres que dijeron haber sufrido violencia de género alguna vez, un $65 \%$ reconocieron no haber denunciado nunca al maltratador. Por otra parte, aunque en 2015 se presentaron 129.123 denuncias en los juzgados de violencia sobre la mujer, y ello supuso un incremento del $1,9 \%$ con respecto a las denuncias presentadas en 2014 (126.742), dichas cifras siguen lejos de las registradas en 2008 (142.125), 2009 (135.540), 2010 (134.105) y 2011 (134.002), tal y como indica el Observatorio de la Violencia de Género. Además de resultar criticable, pensando en que los servicios sociales solo podrán garantizar que quienes denuncian conocen las implicaciones del proceso penal si intervienen con anterioridad ${ }^{3}$, la solución del legislador de 2004 ha resultado, por lo tanto, todo menos efectiva. Parece más correcta, por ello, la línea emprendida en varias Comunidades Autónomas, que no supedita la asistencia a la víctima a la presentación de la correspondiente denuncia, caso de las Leyes 5/2005, de 20 de diciembre, de la Comunidad de Madrid, y 11/2007, de 27 de julio, de Galicia.

Las circunstancias y factores que parecen hallarse detrás de esa actitud reticente de las víctimas han dado pie a no pocos estudios y reflexiones, teóricos y empíricos, especialmente en el ámbito de la criminología. Aunque los resultados alcanzados no son en absoluto concluyentes ${ }^{4}$, la distancia entre victimización y denuncia ha podido explicarse a partir de factores individuales y situacionales.

Así, con arreglo a algunos de ellos, tomar la decisión de denunciar conlleva un desgaste psicológico importante e implica desprenderse de muchos mandatos de género, relacionados con la necesidad de aceptar o de considerar como algo natural padecer

3 Vid. Calle Fernández, Soledad, “Consideraciones sobre la victimización secundaria en la atención social a las víctimas de la violencia de género", Portularia, n. ${ }^{\circ} 4$, Huelva, Universidad de Huelva, 2004, pp. 64 y 65; Quintero Verdugo, MARía IsABel, "La realidad jurídico-social de los delitos de violencia de género", Intervención psicoeducativa en la desadaptación social, n. ${ }^{\circ} 4$, Las Palmas de Gran Canaria, Universidad de Las Palmas de Gran Canaria, 2011, pp. 27 y 28.

4 Vid. Hirschel, David / IRA W. Hutchison, "The Voices of Domestic Violence Victims: Predictors of Victim Preference for Arrest and the Relationship Between Preference for Arrest and Revictimization, Crime and Delinquency, vol. 49, n. ${ }^{\circ}$, Massachusetts, SAGE Publications, 2003, pp. 313 y ss. 
ciertos abusos en la relación de pareja ${ }^{5}$. En esta línea, en un estudio desarrollado en España en 2012, con adolescentes y jóvenes escolarizadas, se concluye que existe una notable discrepancia entre el porcentaje de mujeres que podría ser considerado "técnicamente" como maltratadas y el de las que se describe como tales ${ }^{6}$.

Otra de las explicaciones apuntadas por la literatura es la de que las instituciones que componen el sistema penal no han sido capaces de generar en las víctimas la expectativa de poder obtener una respuesta adecuada, respetuosa, sensible y efectiva a su situación ${ }^{7}$. Tener que revivir los hechos, en la presentación y ratificación de la denuncia, la declaración en las diligencias previas y el juicio oral, bajo la atenta mirada de los funcionarios de la Administración de Justicia, trae consigo una enorme carga de sufrimiento ${ }^{8}$. A muchas mujeres tampoco se les escapa el dato de que tendrán que abandonar el lugar familiar -su lugar de referencia- ${ }^{9}$, iniciar una vida en solitario y asumir nuevas responsabilidades, en no pocas ocasiones sin contar con suficientes recursos económicos. En general, estos temores parecen acentuarse cuando las víctimas pertenecen a minorías étnicas o son inmigrantes ${ }^{10}$. Respuestas más flexibles, que tomen en consideración la voluntad y deseos de las víctimas, tratando de respetar su capacidad de decisión, podrían animarlas a recurrir a la policía ${ }^{11}$. La literatura insiste, asimismo, en que su capacitación y empoderamiento, a través de la puesta a su disposición de información y de recursos, les ayudaría a experimentar la sensación de estar preparadas para enfrentar un proceso judicial con todas las

5 Vid. Ruiz PÉREZ, IsABel et al. "Violencia contra la mujer en la pareja: determinantes y respuestas sociosanitarias”, Gaceta sanitaria, vol. 18, Barcelona, Ediciones Doyma, 2004, p. 7.

6 Vid. Rodríguez Franco, LuIs et al., "Labeling dating abuse: Undetected abuse among Spanish adolescents and young adults", International Journal of Clinical and Health Psychology, vol. 12, n. ${ }^{\circ}$ 1, Granada, Asociación Española de Psicología Conductual, 2012, pp. 55 y ss.

7 Schlesinger Buzawa, Eva / Carl G. Buzawa. Domestic Violence. The Criminal Justice Response, Thousand Oaks, London, New Delhi, SAGE, 2003, pp. 177 y ss.; Albertín Carbó Pilar, et al., "Algunas propuestas psicosociales para abordar el tratamiento de la violencia hacia las mujeres en los contextos jurídico-penales", Anuario de psicología jurídica, vol. 19, Madrid, Colegio Oficial de Psicólogos de Madrid, 2009, pp. 111 y ss.; HeATHER, Douglas. "Battered women's experiences of the criminal justice system: Decentring the law", Feminist Legal Studies, vol. 20, London, Springer, 2012, pp. 121 y ss.

8 Vid. Larrauri Pijoán, Elena, “¿Por qué retiran las mujeres maltratadas las denuncias?”, Revista de Derecho Penal y Criminología, vol. 12, Madrid, Universidad Nacional de Educación a Distancia, 2003 , pp. 288 y ss.

9 Vid. Alonso Grijalba, Edurne, Mujeres víctimas de violencia doméstica con trastorno de estrés postraumático validación empírica de un programa de tratamiento, Madrid, Universidad Complutense de Madrid, 2007, p. 79.

10 Vid. Belur, Jyoti, "Is policing domestic violence institutionally racist? A case study of South Asian Women”, Policing \& Society, vol. 18, n. ${ }^{\circ}$ 4, Oxfordshire, Taylor \& Francis, 2008, p. 436.

11 Vid. Akers, Caroline / Catherine Kaukinen. "The Police Reporting Behavior of Intimate Partner Violence Victims”, Journal of Family Violence, vol. 24, n. ${ }^{\circ}$ 3, Berlin, Heidelberg, Springer, 2009, p.168. 
consecuencias $^{12}$. No en vano, diversos estudios acreditan que muchas mujeres que deciden interponer y mantener una denuncia lo hacen tras haber tomado otras iniciativas al margen del sistema judicial ${ }^{13}$.

Un tercer grupo de factores vendría compuesto por el estado psicológico de shock o angustia en que se hallan las mujeres tras la realización del delito, el entorno de privacidad familiar o de convivencia afectiva (frecuentemente cerrado, secreto) que lo rodea y, en relación con ello, la presión ejercida por terceros (familiares, allegados, compañeros) para que no denuncien ${ }^{14}$.

Entre los motivos que interfieren en la decisión de no denunciar se cuentan asimismo, finalmente, el temor a no ser creídas ante la ausencia, escasez o complejidad de pruebas que puedan confirmar su declaración, el miedo a sufrir represalias y a perder su seguridad económica ${ }^{15} \mathrm{y}$, por último, su deseo de proteger a los allegados y familiares e incluso al propio agresor, al que no se desea, en no pocas ocasiones, perjudicar obligándolo a cumplir una pena que puede traer consigo gravísimas consecuencias económicas, laborales y familiares ${ }^{16}$. En apoyo de esta última hipótesis suele traerse el estudio realizado por Hoyle-Sanders ${ }^{17}$, en el que, aunque más de la mitad de las participantes afirmaron que deseaban que el agresor quedara a disposición judicial, la mayoría declaró, al propio tiempo, no pretender ni querer, con ello, que su pareja fuera imputada, ni que se le exigiesen responsabilidades penales.

Ese concepto cíclico de relación que viven las víctimas es lo que explicaría también, en buena parte de los casos, su decisión de retirar la denuncia y de renunciar, por consiguiente, a continuar con el procedimiento. Un estudio realizado en 2012 mues-

12 Vid. Amant, Dominique et al., "Analyse du processus d'empowerment dans des trajectoires de femmes victimes de violence conjugale à travers le système judiciaire”, Criminologie, vol. 33, n. ${ }^{\circ}$, Montréal, Université de Montréal, 2000, pp. 73 y ss.

13 Vid Cala Carrillo, María Jesús et al., “Por qué algunas mujeres abandonan el procedimiento judicial por violencia de género?: Motivos y factores que influyen en ello", en AA. VV. La renuncia a continuar en el procedimiento judicial en mujeres víctimas de violencia de género: Un estudio en la Comunidad Autónoma Andaluza. CAla CARrillo, María Jesús (comp.), Sevilla, Instituto de la Mujer, 2012, p. 92.

14 Vid. Quintero Verdugo, María Isabel, "La realidad jurídico-social de los delitos de violencia de género", op. cit, p. 29.

15 Vid. Felson, Richard B. et al., "The Reporting of Domestic Violence and Sexual Assault by Nonstrangers to the Police". Journal of Marriage and Family, vol. 67, New Jersey, Wile-Blackwell, 2005, p. 621.597-610; Esther Blay GIL. "Voy o no voy": el recurso a la policía en el caso de la violencia de género. Perspectivas de las víctimas", Estudios Penales y Criminológicos, vol. XXXII, Santiago de Compostela, Universidad de Santiago de Compostela, 2014, p. 382.

16 Vid. Schlesinger Buzawa, Eva / Carl G. Buzawa, Domestic Violence. The Criminal Justice Response, op.cit., pp. 177 y ss.

17 Vid. Hoyle, Carolyn / Andrew Sanders, "Police Response to Domestic Violence", The British Journal of Criminology, vol. 40, Oxford, Oxford University Press, 2000, pp. 14 y ss. 
tra que cuando el procedimiento judicial había sido iniciado por la propia mujer el porcentaje de denuncias era menor, y más pequeño todavía cuando la denuncia se había producido tras una decisión meditada y reflexiva ${ }^{18}$.

Las cifras arrojadas por la investigación que aquí se presenta pueden ayudar a conocer la importancia real -cuando menos, en el contexto geográfico a que se refiere- de algunos de esos motivos, concretamente de los que guardan relación con la "arquitectura interna" de las conductas violentas. No obstante, antes de comentarlas y analizarlas debemos advertir sobre algunas limitaciones inherentes al método de obtención de los datos (y a los datos mismos) que condicionan, indudablemente, su interpretación. Sabemos, en efecto, que hay muchas víctimas que no denuncian a sus agresores, por motivos de diversa índole. Por ello, las estadísticas que a continuación se exponen habrán de utilizarse con suma cautela, so pena de desconocer o minusvalorar el gravísimo problema de la cifra negra de criminalidad existente en este ámbito. Además, y sin desconocer sus muchos aspectos de interés, hay que conceder que la fuente de información que hemos manejado (los expedientes obrantes en la Fiscalía de Área de Santiago de Compostela) no proporciona información sobre indicadores tan valiosos, desde el punto de vista criminológico, como el lugar de interposición de la denuncia por parte de la víctima.

Los expedientes fueron organizados en ocho grupos: i) en función de que su origen se situase en una denuncia de la propia víctima, ii) en una denuncia de sus familiares, iii) en una denuncia de un tercero que hubiera conocido los hechos -incluyendo, bajo ese término, a las personas próximas a la víctima pero carecen de relación de parentesco con ella-, iv) en un atestado de las Fuerzas y Cuerpos de Seguridad acompañado de denuncia de la víctima, v) en un atestado de las Fuerzas y Cuerpos de Seguridad acompañado de denuncia de los familiares de la víctima, vi) en un atestado que sea consecuencia de la intervención directa de las Fuerzas y Cuerpos de Seguridad, vii) en la intervención de los servicios sanitarios (en los supuestos en que se envía un parte médico al decanato de los juzgados, indicándose que se ha prestado asistencia a una mujer que ha podido ser sujeto pasivo de un delito de violencia de género) o, por último, viii) en cualquier otro procedimiento. Esta última categoría abarca los iniciados tras denuncias procedentes de cualquier funcionario o empleado público distinto de los anteriores y que hubiera conocido de la comisión del delito por razón de su profesión, cargo u oficio.

El primero de los datos de interés que arroja nuestro estudio en este apartado (Tabla 1) es el relativo al significativo número de expedientes iniciados tras la intervención

18 Vid. Vid. Cala Carrillo, María Jesús et al. "Conclusiones sobre las renuncias a continuar el procedimiento judicial por violencia de género y propuestas de intervención”, en AA. VV. La renuncia a continuar en el procedimiento judicial en mujeres víctimas de violencia de género: Un estudio en la Comunidad Autónoma Andaluza. Cala Carrillo, María Jesús (comp.), Sevilla, Instituto de la Mujer, 2012, pp. 190 y 191. 
directa de la víctima, esto es, con denuncia o con atestado acompañado de denuncia. En concreto, de cada 10 expedientes concluidos entre los años 2005 y 2012, más de 8 responden a ese esquema. Una primera aproximación a estas cifras permitiría sostener el acierto de las estrategias implementadas en España para propiciar las denuncias de los actos de violencia de género, incluidas las medidas de endurecimiento de las penas y de protección a las víctimas contenidas en la LVG. Hay que seguir dando crédito, no obstante, a quienes sostienen que en la sociedad española impera, todavía, una cierta presión difusa para mantener estos comportamientos en la intimidad. Eso es lo que se deduce de la macroencuesta sobre violencia contra la mujer, realizada, en 2015, a una muestra de 10.171 mujeres representativa de la población femenina residente en España de 16 y más años, y a cuyo tenor un 26,56\% de las encuestadas decidieron no denunciar por miedo, un $21,08 \%$ por vergüenza y un $3,92 \%$ por disuasión por parte de la propia pareja o de un tercero.

Como se ha avanzado, el hecho de que sea la propia víctima la que haya interpuesto la correspondiente denuncia ofrece lecturas e interpretaciones muy variadas. Puede deberse a su voluntad de buscar activamente una vía de salida al "conflicto", de encontrar protección contra futuros actos de violencia, de alcanzar una cierta satisfacción moral - al tener la sensación de que, por fin, se va a reaccionar contra el agresor y sus actos- o, simplemente, de obtener mejoras en su situación o una reparación económica $^{19}$. Sea como fuere, lo que interesa destacar en este momento es que todas y cada una de esas variables son compatibles con la idea, avanzada por criminólogos y sociólogos, de que el mantenimiento o incluso incremento de la tasa de denuncia a lo largo de un período de tiempo como el aquí considerado no es un fenómeno ajeno al grado de confianza que el sistema de justicia penal, en sentido amplio, le merece a las víctimas ni, por consiguiente, a sus propias posibilidades de éxito ${ }^{20}$.

Teóricamente, la afirmación de la naturaleza de delito público de la violencia de género lleva aparejado un mensaje simbólico muy relevante, dirigido, entre otros, a los integrantes de las Fuerzas y Cuerpos de seguridad, para que siempre presenten atestado, al margen de lo que pueda indicar o desear la víctima. El bajo porcentaje de causas iniciadas (de forma unilateral) por la intervención directa de aquellos apenas un 11,21\%- parece confirmar, sin embargo, la opinión de quienes sostienen que, en la práctica, no parece sencillo que la policía dé curso a los incidentes en los

19 Vid. Felson, Richard B. et al., "The Reporting of Domestic Violence and Sexual Assault by Nonstrangers to the Police", op. cit., pp. 619 y 620.

20 Vid. Schlesinger Buzawa, Eva / Carl G. Buzawa, Domestic Violence. The Criminal Justice Response, op. cit.,pp. 177 y ss.; AlBerTín CARBó, PILAR et al., "Algunas propuestas psicosociales para abordar el tratamiento de la violencia hacia las mujeres en los contextos jurídico-penales", op . cit., pp. 111 y ss.; Heather, Douglas. "Battered women's experiences of the criminal justice system: Decentring the law", op. cit., pp. 121 y ss. 
casos en que la mujer manifiesta su voluntad de no denunciar ${ }^{21}$. Poco relevante es, igualmente, la proporción de procesos que tienen su origen en la denuncia de un familiar de la víctima, o en un atestado policial con denuncia de un familiar, un 1,21\%, a pesar de que estos delitos se producen, normalmente, en el entorno familiar y de que aquellos pueden ser perfectamente, por lo tanto, testigos directos de los hechos o de otros que guardan relación con ellos (por ejemplo, del estado emocional y físico de las partes, de la presencia de vestigios o signos de la agresión...). El dato es consistente, en cualquier caso, con las estadísticas publicadas por el Observatorio de la Violencia de Género ${ }^{22}$. A la hora de interpretarlo habrán de traerse a colación, junto con los aspectos socio-culturales a que se ha hecho referencia, factores como el de los costes que acarrean las sanciones penales para toda la familia o el temor a producir una desestructuración familiar ${ }^{23}$.

\section{Tabla 1}

\begin{tabular}{|l|r|r|}
\cline { 2 - 3 } \multicolumn{1}{c|}{} & Fr. Absoluta & \% \\
\hline Denuncia presentada por la víctima & 182 & $31,38 \%$ \\
\hline Denuncia presentada por la familia & 8 & $1,38 \%$ \\
\hline Denuncia presentada por terceros & 9 & $1,55 \%$ \\
\hline Atestado policial con denuncia de la víctima & 297 & $51,21 \%$ \\
\hline Atestado policial con denuncia de la familia & 3 & $0,52 \%$ \\
\hline Atestado policial con intervención directa policial & 66 & $11,38 \%$ \\
\hline Parte de lesiones & 16 & $2,76 \%$ \\
\hline Otros & 4 & $0,69 \%$ \\
\hline
\end{tabular}

Fuente: Expedientes obrantes en la Fiscalía de Área de Santiago de Compostela.

Por lo que se refiere a las denuncias que provienen de partes de lesiones, la literatura ha destacado las dudas y dilemas de todo orden (también éticos) que embargan a los profesionales sanitarios encargados de su elaboración, que se encuentran en la disyuntiva de cumplir con la obligación de denunciar o con la de garantizar a la mujer la asistencia que precisa y lograr su confianza ${ }^{24}$. En este caso, las cifras que

21 Vid. Armero Villalba, Silvia, "Diligencias de prueba. Rectractación de las víctimas. La protección de la víctima en el curso del proceso", en AA. VV. Estudios sobre violencia familiar y agresiones sexuales, vol. 2. Ministerio De Justicia (comp.), Madrid, Centro de Estudios Jurídicos de la Administración de Justicia, 2004, pp. 55 y ss.

22 Los datos proporcionados por el Observatorio son los siguientes: $2017: 2,05 \% ; 2016$ : 1,44\%; 2015 : 2,25\%;2014: 1,63\%; 2013: 1,50\%; 2012: 1,26\%; 2011: 1,15\% (www.poderjudicial.es/cgpj/es/Temas/ Violencia-domestica-y-de-genero/Actividad-delObservatorio/Datos-estadisticos/).

23 Vid. Hoyle, Carolyn / Andrew Sanders, "Police Response to Domestic Violence", op. cit., p. 15; Blay GiL, Esther, "Voy o no voy": el recurso a la policía en el caso de la violencia de género. Perspectivas de las víctimas", op. cit., p. 385.

24 Vid. Aretio Romero, Antonia, "Aspectos éticos de la denuncia profesional de la violencia contra las mujeres, Gaceta Sanitaria, vol. 21, n. ${ }^{\circ}$ 4, Barcelona, Ediciones Doyma, 2007, pp. 273 y ss. 
arroja nuestro estudio son claramente inferiores a las que muestra el Observatorio de Violencia del CGPJ a nivel nacional ${ }^{25}$.

Hemos podido comprobar, asimismo, que hay una serie de rasgos sociodemográficos que incentivan o refuerzan la decisión de no interponer denuncia (Tabla 2). Concretamente, los que se muestran como estadísticamente significativos a ese respecto son la convivencia en pareja con el agresor ( $\mathrm{p}$-valor $=0,0195)$, la convivencia con familiares ( $\mathrm{p}$-valor $=0,0339$ ), el hecho de compartir el domicilio con los hijos (p-valor $=0,0048) \mathrm{y}$, por último, la titularidad en propiedad de la vivienda en la que la víctima convive con el agresor (p-valor=0,0147). Ese hallazgo debe servir para alertar sobre la necesidad de intensificar las estrategias de apoyo e intervención en el colectivo de mujeres víctimas que han tomado la decisión de interponer denuncia, en solitario o conjuntamente con las Fuerzas y Cuerpos de seguridad. La pretensión última debe ser la de que el transcurso del tiempo no haga posible el ejercicio de presiones -en especial en los supuestos mencionados, así como, en general, en todos aquellos otros en que se mantiene la relación afectiva con el agresor-, dando al traste con los esfuerzos por aportar pruebas en relación con los dos elementos de estos delitos que presentan mayores dificultades en ese terreno: la violencia psicológica y la habitualidad.

Tabla 2

\begin{tabular}{|c|c|c|c|c|c|}
\hline & \multicolumn{2}{|c|}{$\begin{array}{c}\text { La víctima no presenta } \\
\text { denuncia }(\mathrm{N}=398)\end{array}$} & \multicolumn{2}{|c|}{$\begin{array}{l}\text { La víctima presenta } \\
\text { denuncia }(N=182)\end{array}$} & \multirow{2}{*}{ p-valor } \\
\hline & $\begin{array}{c}\text { Fr. } \\
\text { Absoluta }\end{array}$ & $\%$ & $\begin{array}{c}\text { Fr. } \\
\text { Absoluta }\end{array}$ & $\%$ & \\
\hline \multicolumn{6}{|c|}{ Conviven en pareja } \\
\hline No & 157 & $39,45 \%$ & 91 & $50,00 \%$ & \multirow[t]{3}{*}{0,0195} \\
\hline Sí & 232 & $58,29 \%$ & 91 & $50,00 \%$ & \\
\hline Desconocido & 9 & $2,26 \%$ & 0 & $0,00 \%$ & \\
\hline \multicolumn{6}{|c|}{ Domicilio compartido con: } \\
\hline \multicolumn{6}{|l|}{ Con los hijos } \\
\hline No & 234 & $58,79 \%$ & 107 & $58,79 \%$ & \multirow[t]{3}{*}{0,0048} \\
\hline Sí & 146 & $36,68 \%$ & 66 & $36,26 \%$ & \\
\hline Desconocido & 18 & $4,52 \%$ & 9 & $4,95 \%$ & \\
\hline
\end{tabular}

25 Los datos publicados por el Observatorio son: 2017: 9,74\%; 2016: 10,15\%; 2015: 11,28\%; 2014: 11,86\%; 2013: 11,50\%; 2012: 11,47\%; 2011: 11,41\%; 2010: 10,92\%; 2009: 11,9\%; 2008: 11,6\%. Vid. www.poderjudicial.es/cgpj/es/Temas/Violencia-domestica-y-de-genero/Actividad-del-Observatorio/ Datos-estadisticos/ 


\begin{tabular}{|c|c|c|c|c|c|}
\hline & \multicolumn{2}{|c|}{$\begin{array}{c}\text { La víctima no presenta } \\
\text { denuncia }(\mathrm{N}=398)\end{array}$} & \multicolumn{2}{|c|}{$\begin{array}{l}\text { La víctima presenta } \\
\text { denuncia }(N=182)\end{array}$} & \multirow{2}{*}{ p-valor } \\
\hline & $\begin{array}{c}\text { Fr. } \\
\text { Absoluta }\end{array}$ & $\%$ & $\begin{array}{c}\text { Fr. } \\
\text { Absoluta }\end{array}$ & $\%$ & \\
\hline No & 346 & $86,93 \%$ & 156 & $85,71 \%$ & \multirow[t]{3}{*}{0,0339} \\
\hline Sí & 34 & $8,54 \%$ & 17 & $9,34 \%$ & \\
\hline Desconocido & 18 & $4,52 \%$ & 9 & $4,95 \%$ & \\
\hline \multicolumn{6}{|l|}{ Con otras personas } \\
\hline No & 369 & $92,71 \%$ & 170 & $93,41 \%$ & \multirow[t]{3}{*}{0,0525} \\
\hline Sí & 11 & $2,76 \%$ & 3 & $1,65 \%$ & \\
\hline Desconocido & 18 & $4,52 \%$ & 9 & $4,95 \%$ & \\
\hline \multicolumn{6}{|l|}{ Tipo de vivienda } \\
\hline Piso & 131 & $32,91 \%$ & 54 & $29,67 \%$ & \multirow[t]{5}{*}{0,1405} \\
\hline Casa & 86 & $21,61 \%$ & 31 & $17,03 \%$ & \\
\hline Bajo & 12 & $3,02 \%$ & 3 & $1,65 \%$ & \\
\hline Pensión & 3 & $0,75 \%$ & 0 & $0,00 \%$ & \\
\hline Desconocido/no conviven & 166 & $42,71 \%$ & 94 & $51,65 \%$ & \\
\hline \multicolumn{6}{|l|}{ Propiedad de la vivienda } \\
\hline Propiedad & 98 & $24,62 \%$ & 34 & $18,68 \%$ & \multirow[t]{3}{*}{0,0147} \\
\hline Alquiler/otros & 84 & $21,11 \%$ & 25 & $13,74 \%$ & \\
\hline Desconocido/no conviven & 256 & $54,27 \%$ & 123 & $67,58 \%$ & \\
\hline Años de convivencia: media & \multicolumn{2}{|c|}{$9,42696(11,93)$} & \multicolumn{2}{|c|}{$9,940717(11,27)$} & 0,1023 \\
\hline
\end{tabular}

Fuente: Expedientes obrantes en la Fiscalía de Área de Santiago de Compostela.

\section{LA VÍCTIMA-TESTIGO}

Una de las peculiaridades de los procesos penales por delitos de violencia contra la mujer estriba en los considerables obstáculos probatorios a que deben enfrentarse la fiscalía y el juez (para alcanzar su convicción). Al producirse los hechos, en la gran mayoría de los supuestos, en el hogar familiar, la única que los conoce es, frecuentemente, la propia víctima, lo que significa tanto como los únicos elementos de prueba directa y personal con que podrá contarse serán las declaraciones realizadas por el imputado -habitualmente en sentido exculpatorio- y las manifestaciones de aquella -de carácter incriminatorio-, consideradas por los artículos 109 y 110 de la LECrim como declaración de parte ${ }^{26}$. Por otra parte, la implicación de familiares y

26 Vid. Chinchilla Baricarte, María José et al., "Construcción de los hechos desde la prueba en procedimientos de violencia doméstica", en AA. vV. Terceras jornadas internacionales sobre Derechos y libertades fundamentales. GARcía INDA, ANDRÉs / EMANUELA LOMBARDO (comp.), Zaragoza, Editorial Mira, 2001,p. 18; MirentXu CorCOY BidAsolo, "Ley y violencia de género. Problemática jurídicopenal y político-criminal de la regulación de la violencia de género y doméstica”, InterseXiones, n. ${ }^{\circ}$ 1, Vigo, Universidad de Vigo, 2010, pp. 152 y ss.; Olaizola NoGales, InÉs, "Violencia de género: 
vecinos en estos procesos es, todavía, escasa, probablemente porque todavía entienden que se trata de asuntos privados.

Parece imprescindible, en consecuencia, que las víctimas de la violencia declaren durante la instrucción y testifiquen y ratifiquen dichas declaraciones en el transcurso del juicio oral. Sus comportamientos suelen responder, no obstante, a un patrón poco convencional $^{27}$, traduciéndose, en muchas ocasiones, en actuaciones y declaraciones incoherentes y hasta contradictorias. Se trata de víctimas que se retractan, se niegan a declarar, rechazan las sentencias, facilitan el quebrantamiento de las prohibiciones de alejamiento... Detrás de esas actitudes se halla, también, sin duda, la existencia de vínculos personales, vitales y afectivos con el agresor (en ocasiones simultáneos, incluso, al desarrollo del proceso). Quizá, por ello, el legislador español ha resuelto “desconocer" drásticamente su propia voluntad en ciertos procedimientos o trámites, al permitir, por ejemplo, que sean otros quienes soliciten (para ellas, se entiende) la orden de protección, excluir que sus cambios de opinión sean causa de revocación de dicha orden o imponer de manera obligatoria determinadas reglas de conducta, como la prohibición de aproximación y las órdenes de alejamiento. Este modus operandi parece dar la razón a quienes observan -muy críticamente- que el sistema español de protección frente a la violencia de género se orienta al cumplimiento de fines más elevados que el de ser un mero instrumento de lo que buscan las víctimas, de sus temores y dudas ${ }^{28}$.

La LVG ha previsto algunas medidas para poner a disposición de las víctimas, por medio de los correspondientes equipos técnicos de ayuda, un sistema de apoyo continuado, desde el momento de la denuncia hasta el de la celebración del juicio oral. Aunque diversos trabajos avalan su eficacia, los técnicos y especialistas coinciden en destacar su insuficiencia para prevenir las situaciones anteriormente referidas, insistiéndose en la necesidad de mejorar, con carácter general, los sistemas de protección, información y asistencia social y letrada, así como en la de garantizar la coordinación de las actividades de todos los profesionales que intervienen en la fase de investigación del proceso. La reivindicación de la utilidad y operatividad de los protocolos de actuación -y la exigencia de su seguimiento- a la hora de elaborar los expedientes instructores es lugar común, en este sentido, en la literatura y en la praxis. En cambio, las recomendaciones de algunos fiscales de recurrir al art. 420

elementos de los tipos penales con mayor dificultad probatoria", Estudios penales y criminológicos, vol. XXx, Santiago de Compostela, Universidad de Santiago de Compostela, 2010, pp. 279 y ss

27 Vid. Larrauri PijoÁn, Elena, Criminología crítica y violencia de género, Madrid, Trotta, 2007, pp. 102 y ss.; LAurenzo Copello, PATricia, "La violencia de género en el Derecho penal: un ejemplo de paternalismo punitivo", en AA. vV. Género, Violencia y derecho. LAUREnZo CoPELlo, PATRICIA et al. (comp.), Valencia, Tirant lo Blanch, 2008, pp. 356 y ss.; Olga Fuentes Soriano. El enjuiciamiento de la violencia de género, Madrid, Iustel, 2009, p. 127.

28 Vid. Laurenzo Copello, Patricia, "La violencia de género en el Derecho penal: un ejemplo de paternalismo punitivo", op. cit., pp. 328 y ss. 
LECrim para imponerle una multa a la víctima-testigo que no acuda a declarar o, incluso, a los artículos 463, 456 y 458 del Código penal para procesarla como responsable de obstrucción a la justicia, acusación y denuncia falsa o falso testimonio, respectivamente, han hallado, por lo que alcanzo a ver, escaso eco ${ }^{29}$.

También se ha llamado la atención sobre el dato de que, generalmente, entre el momento de interposición de la denuncia y el de celebración del juicio oral transcurrirá un período de tiempo generoso, que puede precipitar el riesgo de inasistencia al acto del juicio oral o el de modificación de lo declarado en la fase de instrucción -cuando no el de que se haga uso de la facultad de dispensa prevista en el artículo $416.1^{\circ}$ de la LECrim-. Frente a ello se han venido presentando diversas fórmulas y propuestas dirigidas a favorecer sistemas de captación del testimonio que, con pleno respeto a las garantías procesales, permitan su recogida inmediata y minimicen, en la medida de lo posible, el peligro de que se produzca una modificación del relato de los hechos y la angustia provocada por la espera del día fijado para el juicio oral: reducir las comparecencias; evitar todo contacto visual directo entre las partes, empleando medios audiovisuales; interponer una mampara; eliminar los datos relativos a la identidad o a la localización de la víctima-testigo en los autos; establecer legalmente su domicilio en la sede del propio juzgado, etc ${ }^{30}$. Todas ellos cuentan con cobertura legal en la Ley Orgánica 19/1994, de 23 de diciembre, de Protección a Testigos y Peritos en Causas Criminales, y en la LO 14/1999, de reforma de la LECrim en materia de protección a las víctimas de malos tratos. Esta última sanciona la posibilidad de extender el régimen de excepcionalidad de los careos y de la confrontación visual entre el testigo y el acusado a todos los casos en que se acredite una situación de especial dependencia psíquica o de temor racional y justificado, entre ambos, aunque el primero (la primera) sea mayor de edad.

La valoración de la suficiencia y aptitud del testimonio de la víctima compete al juez sentenciador, en el bien entendido de que, de cualquier modo, supondrá un elemento probatorio más, o sea, sin virtualidad para desvirtuar de forma automática la presunción de inocencia del imputado. Conviene recordar, a este respecto, que el Tribunal Supremo ha venido determinando los parámetros mínimos a los que debe

29 Vid. Medina Ariza, JuAn José, Violencia contra la mujer en la pareja. Investigación comparada y situación en España, Valencia, Tirant lo Blanch, 2002, p. 534; LARrauri PiJoÁn, ElenA, Criminología crítica y violencia de género, op. cit., p. 103; LAURENZO CoPEllo, PATRICIA, "La violencia de género en el Derecho penal: un ejemplo de paternalismo punitivo”, op. cit., p. 335.

30

Vid. Mirentxu Corcoy BidAsolo, "Ley y violencia de género. Problemática jurídico-penal y políticocriminal de la regulación de la violencia de género y doméstica”, op. cit., p. 159; FERNÁNDEZ-FIGARES Molares, María José, "La fuerza probatoria del testimonio de la víctima en la condena por delitos de violencia contra la mujer", Revista Internauta de Práctica Jurídica, vol. 28, Valencia, Asociación de Juristas Valencianos, 2012, pp. 36 y ss.; IBÁÑEZ DíEZ, PAUlA, "La declaración de la perjudicada en los procedimientos de Violencia de Género: una aproximación crítica desde el ejercicio de la abogacía", Journal of Feminist, Gender and Women Studies, $\mathrm{n}^{\circ}$ 1, Madrid, Universidad Autónoma de Madrid, 2015, p. 70. 
ajustarse la declaración de la denunciante para constituirse en (única) prueba de cargo: el de la ausencia de incredulidad subjetiva, el de la constatación objetiva de la existencia de los hechos (verosimilitud de la declaración) y, por último, el de la persistencia en la incriminación (STS 16/02/1998; STS 23/03/1999; sTS 19/06/1999; STS 02/10/1999). El segundo de los extremos podrá establecerse con ayuda de las llamadas corroboraciones periféricas de naturaleza objetiva -como las conclusiones del informe médico-, así como de un adecuado conocimiento sobre el estado de capacitación de la víctima (tanto en el momento en que sucedieron los hechos, como en el de prestar testimonio en el juicio oral). Por su parte, la persistencia en la incriminación, o, lo que es lo mismo, la ausencia de contradicciones y ambigüedades en ella y su carácter prolongado en el tiempo, podrá acreditarse a través del correspondiente interrogatorio y de las preguntas formuladas durante el plenario.

Comentario aparte merece el problema de la retractación, en el juicio oral, del relato realizado durante la instrucción del procedimiento y del valor probatorio de estas últimas. De acuerdo con la jurisprudencia mayoritaria, no hay nada que impida que dichas declaraciones se introduzcan en el plenario mediante su lectura en virtud del artículo 714 LECrim. Una vez sometidas a los requisitos de oralidad, inmediación, contradicción y publicidad, el órgano judicial que ha de dictar la sentencia tendrá libertad para ponderar ambos relatos y decidir a cuál le otorga mayor credibilidad ${ }^{31}$. Mayores problemas suscita la valoración de la declaración policial de la víctima en los casos en que se retracta de su primer relato en el acto del juicio oral. Esta cuestión excede, no obstante, de los límites de este trabajo.

A tenor de los datos que arrojan los expedientes de la Fiscalía de Área de Santiago de Compostela, la víctima comparece y declara como testigo (sea a favor, sea en contra del imputado) en la gran mayoría de los casos (Tabla 3). El hecho de que el proceso se hubiese iniciado mediando o no una denuncia suya no supone un factor que interfiera significativamente en esa decisión (p-valor=0,2872): en el primer caso, el porcentaje de víctimas-testigos se eleva a un 88,10\% (n=422), para apenas disminuir hasta un $83,17 \%(n=84)$ cuando lo que ha puesto en marcha el expediente es una denuncia de un tercero, un parte de lesiones, un atestado policial o una denuncia interpuesta por familiares.

31 Vid. Sts 25/01/2008; De Hoyos SANCHO, Monserrat, "Nuevas tendencias en la investigación y prueba de los delitos de violencia doméstica y de género", en AA.vV. La reforma de la justicia penal. Arangüena, Coral / Ángel Sanz Morán (comp.), Valladolid, Lex Nova, 2008, pp. 446 y ss.; Fuentes Soriano, Olga, El enjuiciamiento de la violencia de género, op . cit., p. 136. 


\section{Tabla 3}

\begin{tabular}{|c|c|c|c|c|c|}
\hline & \multicolumn{2}{|c|}{$\begin{array}{l}\text { La víctima no presenta } \\
\text { denuncia }(\mathrm{N}=101)\end{array}$} & \multicolumn{2}{|c|}{$\begin{array}{l}\text { La víctima presenta } \\
\text { denuncia }(N=479)\end{array}$} & \multirow[t]{2}{*}{ p-valor } \\
\hline & Fr. Absoluta & $\%$ & Fr. Absoluta & $\%$ & \\
\hline \multicolumn{6}{|c|}{ Testimonio de la víctima } \\
\hline No & 17 & $16,83 \%$ & 56 & $11,69 \%$ & \multirow[t]{3}{*}{0,2872} \\
\hline Sí & 84 & $83,13 \%$ & 422 & $88,10 \%$ & \\
\hline Desconocido & 0 & $0,00 \%$ & 1 & $0,21 \%$ & \\
\hline
\end{tabular}

Fuente: Expedientes obrantes en la Fiscalía de Área de Santiago de Compostela.

Nuestro estudio pone de manifiesto, además, que no existe una relación estadísticamente significativa entre la decisión de la víctima prestar testimonio o la de modificarlo o retractarse en él, por una parte, y sus condiciones socio-económicas o el hecho de que conviva o no con el agresor, por otra. En cambio, sí hemos podido comprobar (Tabla 4) la incidencia del factor años de convivencia en la negativa de la víctima a declarar ( $\mathrm{p}$-valor= 0,0105): las víctimas que ejercen ese derecho convivieron más años con el agresor (una media de 12,039$)$ que las que no lo hicieron $(9,184)$. Este dato nos parece especialmente significativo.

Tabla 4

\begin{tabular}{|l|c|c|c|c|c|}
\hline & \multicolumn{4}{|c|}{ La víctima ejerce el derecho a no declarar } \\
\hline & \multicolumn{2}{|c|}{ Sí (N=86) } & \multicolumn{2}{|c|}{ No (N=494) } & \multirow{2}{*}{ p-valor } \\
& $\begin{array}{c}\text { Fr. } \\
\text { Absoluta }\end{array}$ & $\%$ & $\begin{array}{c}\text { Fr. } \\
\text { Absoluta }\end{array}$ & $\%$ & \\
\hline Años de convivencia: media (DE) & \multicolumn{2}{|c|}{12,039} & $(11,25)$ & $9,184(11,76)$ & 0,0105 \\
\hline
\end{tabular}

Fuente: Expedientes obrantes en la Fiscalía de Área de Santiago de Compostela.

\section{LA VÍCTIMA Y LA DISPENSA LEGAL DE DECLARAR}

A tenor de los arts. 416 y 707 LECrim, y con independencia de que haya interpuesto o no denuncia, la mujer se halla dispensada de cumplir con el deber de declarar en fase de instrucción y de juicio oral, respectivamente, siempre que medie relación conyugal o -tras la Ley 13/2009, de 3 de noviembre, de reforma de la legislación procesal para la implantación de la Nueva Oficina Judicial-relación de hecho análoga a la matrimonial. Con arreglo al art. 416.1 LEcrim, en concreto, la dispensa asiste a "los parientes del procesado en línea directa ascendente y descendente, su cónyuge, o persona unida por relación de hecho análoga a la matrimonial, sus hermanos consanguíneos, o uterinos y los laterales consanguíneos hasta el segundo grado civil, así como los parientes naturales a que se refiere el número 3 del artículo 261”. 
Es obligatorio advertir formalmente a la víctima-testigo, antes de su declaración, en la fase de instrucción y en el acto del juicio oral, de la posibilidad de hacer uso de ella en cualquier momento, sin que el hecho de que no se hubiera hecho valer en declaraciones anteriores pueda suponer renuncia tácita -y definitiva- alguna a su utilización en una fase posterior. Ese deber de información corre a cargo del juez instructor, competiéndole al secretario judicial del juzgado de instrucción o del de violencia contra la mujer consignar lo indicado por aquella. En principio, la no observancia de estas previsiones trae consigo la nulidad de la diligencia y de la prueba por infracción de lo indicado en el artículo 11 de la Ley Orgánica del Poder Judicial ${ }^{32}$, si bien la Jurisprudencia ha venido excepcionando esa regla en ciertos supuestos. Es el caso del descrito en la STC 94/2010, de 15 de noviembre de 2010, a cuyo tenor, a pesar de que no había sido informada de su derecho a la dispensa, difícilmente podía entenderse que la esposa del acusado no había ejercido voluntariamente la opción que resulta del art. 416 LECrim, al tratarse, justamente, de "la promotora de la acusación contra su marido, habiéndose personado en la causa como acusación particular y habiendo solicitado para él la imposición de graves penas, pues si su dilema moral le hubiera imposibilitado perjudicar con sus acciones a su marido no habría desplegado contra él la concluyente actividad procesal reveladora de una, al menos, implícita renuncia a la dispensa que le confería el art. 416 LECrim”.

Por lo que se refiere al fundamento legal del derecho a la dispensa del deber de declarar, tanto la jurisprudencia como la doctrina trabajan, fundamentalmente, con dos líneas de argumentación. La primera alude a la no exigibilidad de una conducta diferente a la de mantener silencio, ya sea por los vínculos de solidaridad familiar (o casi familiar) que existen entre la testigo y el imputado, ya por la necesidad de proteger la intimidad del ámbito familiar, con arreglo a lo dispuesto por el artículo $18 \mathrm{CE}^{33}$. La segunda apunta a razones de tipo pragmático, subrayándose que las advertencias a la víctima sobre su deber de declarar resultan estériles en situaciones tan particulares, en que quien debería respaldar la acusación es un(a) pariente del imputado ${ }^{34}$.

Sea como fuere, el régimen legal que acaba de exponerse -sucintamente- es objeto de controversia entre los operadores jurídicos. Las cifras sobre renuncias de las mujeres a la continuación de los procesos penales en los que son víctimas, es decir, al

32 Vid. STS 17/10/1007; sAP Gerona 06/04/2005; SAP Sevilla 12/01/2007; RuBy SiBONY et al. "La prueba y la dispensa del deber de declarar por la testigo-víctima en los procesos de violencia de género", $L a$ Toga , n. ${ }^{\circ}$ 182, Sevilla, Ilustre Colegio de Abogados de Sevilla, 2011, pp. 13 y ss.

33 Vid. STS 22/02/2007; Pelayo LAVÍn, MARTA, “¿Es necesaria una reforma del art. 416 LECrim. para luchar contra la violencia de género?", en AA. VV. Tutela jurisdiccional frente a la violencia de género: aspectos procesales, civiles, penales y laborales. DE Hoyos SANCHO, MONTSERRAT (comp.), Valladolid, Lex Nova, 2009, pp. 505 y ss.

34 Vid. Piñeiro Zabala, IGOR, "La víctima de la violencia de género y la dispensa del artículo 416 de la Lecrim”, Revista Jurídica de Castilla León, vol. 24, Valladolid, Junta de Castilla y León, 2011, pp. 97 y ss. 
legítimo derecho de ejercer su acción penal contra su agresor, son muy significativas. Los estudios estadísticos y de campo insisten en que la negativa a declarar propicia una cascada de sentencias absolutorias y de sobreseimientos, lo que significa tanto como que el silencio de la víctima termina por prestar cobertura -y facilitar la huida del proceso- al agresor ${ }^{35}$. Se ha sostenido, por ello, la necesidad de proceder a su reforma, sugiriéndose al respecto diversas líneas de intervención, orientadas todas ellas, de una manera u otra, a acotar o reducir la excesiva discrecionalidad judicial que parece presidirlo ${ }^{36}$.

Una de esas propuestas, no exenta de críticas, por cierto, procede del grupo de expertas y expertos en violencia doméstica y de género del Consejo General del Poder judicial, que apuesta por distinguir los casos en que la testigo es víctima de violencia de género de aquellos otros en que los delitos y faltas en cuestión no proceden de personas vinculadas a ella por las relaciones de parentesco descritas en el art. 416 LECrim. En este mismo sentido se pronuncian Magro Servet, que defiende, directamente, la exclusión del ámbito de aplicación de este último precepto de las víctimas-testigos, con la finalidad de "ampliar y garantizar" la seguridad jurídica y de ampliar su marco de protección, y los autores de la Propuesta de Anteproyecto de la LECrim $^{37}$. Al objeto de evitar fraudes de ley, dicha propuesta prevé que la exención de la obligación de declarar por razón de parentesco "no será aplicable cuando las personas... hayan aceptado declarar durante el procedimiento después de haber sido debidamente informadas de su derecho a no hacerlo" 38 .

En cualquier caso, hay que conceder que la relación existente entre los principios de autonomía de la voluntad de las víctimas de violencia de género y de

35 Vid. Gudín Rodríguez-Magariños, Faustino, "El silencio procesal de las víctimas: ¿caballo de troya para futuros maltratos?", Actualidad Jurídica Aranzadi, n 769, Cizur Menor, Thomson ReutersAranzadi, 2009, pp. 1 y ss.; Miranda Estrampes, Manuel, "Particularidades de la prueba en los delitos de violencia de género", en AA. VV., Tutela jurisdiccional frente a la violencia de género: aspectos procesales, civiles, penales y laborales. De Hoyos SANCHO, MonTSERRAT (comp.), Valladolid, Lex Nova, 2009, p. 458; SERrano Hoyo, Gregorio, "Sobre las posibles conductas procesales de la mujer víctima de delitos de violencia de género", Anuario de la Facultad de Derecho de la Universidad de Extremadura, vol. XXVIII, Cáceres, Universidad de Extremadura, 2010, p. 153.

36 Vid. Magro Servet, Vicente, "La imposibilidad de conceder a las víctimas de la violencia de género la dispensa de declarar contra sus agresores (artículo 416 LECrim): ¿Es necesaria una reforma legal?”. La Ley, n 4, Madrid, Wolters Kluwer, 2005, pp. 1.697 y ss.; Pelayo Lavín, Marta, “¿Es necesaria una reforma del art. 416 LECrim. para luchar contra la violencia de género?”, op. cit., pp. 507 y 508; Ruby SiBONY et al. "La prueba y la dispensa del deber de declarar por la testigo-víctima en los procesos de violencia de género", op. cit., p. 18.

37 Vid. Magro Servet, Vicente, "La imposibilidad de conceder a las víctimas de la violencia de género la dispensa de declarar contra sus agresores (artículo 416 LECrim): ¿Es necesaria una reforma legal?”, op. loc. cit.

38 Vid. Magro Servet, Vicente, "La imposibilidad de conceder a las víctimas de la violencia de género la dispensa de declarar contra sus agresores (artículo 416 LECrim): ¿Es necesaria una reforma legal?”, op. loc. cit. 
tutela legal de quienes sufren situaciones de dominación es todo menos pacífica y que se abre a tensiones y discordancias para las que no cabe soluciones únicas ni, mucho menos, sencillas.

Desde luego, a la hora de proceder a un análisis del tema deben tenerse presentes diversos aspectos. Así, por una parte, parece claro, y así lo indican la doctrina y la jurisprudencia, que si la participación de la víctima en la maquinaria procesal se dejase totalmente a su arbitrio, se estaría sancionando la no penetración del Derecho penal en el ámbito familiar, incluso cuando se estuviese ante delitos públicos o semipúblicos. La sentencia de la Audiencia Provincial de Madrid, Sección 27, de 31 de marzo de 2009, expone de una forma muy gráfica e ilustrativa este punto de vista. Por otra parte, sin embargo, parece que forzar a la denunciante a deponer testimonio en el acto del juicio podría conducir a su imputación como autora de un delito de desobediencia o de falso testimonio, por causa de la divergencia de las declaraciones que pueda realizar en la fase de instrucción y en el juicio oral ${ }^{39}$. Tampoco puede pasarse por alto, en fin, el dato de que la exclusión de plano de las víctimas de violencia de género del campo de aplicación de la dispensa del art. 416 generará dudas razonables de inconstitucionalidad, sobre todo si es que, efectivamente, se parte de la base de que el principal fundamento de aquella sehalla en el art. 24. 2 CE. La STS 134/2007, de 22 de febrero, hace eco de esta idea.

Otra de las cuestiones que debe ser examinada es la relativa a la determinación del momento en que las víctimas pueden acogerse a la dispensa, teniendo en cuenta que las circunstancias o situaciones que hacen posible su ejercicio no tienen por qué estar vigentes durante toda la duración del proceso penal. Es muy posible, por ejemplo, que la víctima sí sea cónyuge del agresor en el momento en que se interpone la denuncia o en que se produce la declaración ante el juez de instrucción, pero que al tener lugar la declaración en el juicio oral ya sea firme la sentencia de divorcio o no subsista el vínculo afectivo o la situación de pareja de hecho.

Las opiniones sobre este punto no son, de nuevo, unánimes. Tratando de sistematizarlas, diré que para un sector es imprescindible que la circunstancia o situación que da fundamento a la dispensa subsista en el momento de declarar, debiendo radiarse del precepto, en consecuencia, los casos de quiebra definitiva de la misma. En cambio, las quiebras temporales -en las que finalmente se produce una reconciliación de la pareja- sí deberían enervar su aplicación, so pena -como explica la STS (Sala 2a) 164/2008, de 8 de abril- de dar al traste con el derecho a la tutela judicial efectiva, por privar al Ministerio Fiscal (ilegalmente) de una prueba que podría ser esencial

39 Vid. Miranda Estrampes, Manuel, "Particularidades de la prueba en los delitos de violencia de género”, op . cit., p. 460; PELAYO LAVÍn, MARTA, “¿Es necesaria una reforma del art. 416 LECrim. para luchar contra la violencia de género?", op. cit., pp. 508 y 509; SERrano Hoyo, Gregorio, "Sobre las posibles conductas procesales de la mujer víctima de delitos de violencia de género”, op. cit., p. 138. 
para acreditar la existencia del delito objeto de acusación. Mayor flexibilidad exhibe la sentencia de 26 de julio de 2012, Sección 27, de la Audiencia Provincial de Madrid, que lleva a cabo un interesante análisis de las sentencias interpretativas del Tribunal Supremo sobre la figura de la dispensa. A título de conclusión, la sentencia señala que los vínculos de parentesco deben existir al realizarse la declaración, salvo cuando el testimonio pueda comprometer la intimidad familiar existente en el momento de producirse la agresión, en cuyo caso también procederá reconocerle a la víctima la facultad de hacer valer lo previsto en el art. 416.

Menos polémica es la imposibilidad de hacer revivir las declaraciones sumariales una vez que se ha hecho uso de la dispensa en el juicio oral. Ciertamente, la víctima puede haber prestado, en fase de instrucción, una declaración claramente incriminatoria, para decidir acogerse posteriormente a la dispensa en el plenario, si es que conserva su relación matrimonial (o casi matrimonial) con el agresor. Pues bien, tanto la doctrina como la jurisprudencia del Tribunal Supremo se han pronunciando en contra de la posibilidad de incorporar las declaraciones testificales prestadas en el sumario a la actividad probatoria del juicio oral por la vía de los artículos 714 o 730 LECrim $^{40}$. Dos son los argumentos materiales que se traen en apoyo de esta postura: el del efecto desvirtuador que supondría, para el derecho a la dispensa, la lectura de las declaraciones sumariales ante el silencio del testigo-víctima en el juicio oral, y el del perjuicio irrogado al derecho a la defensa del inculpado, al que se privaría de la facultad de interrogar a un testigo esencial, con las necesarias garantías derivadas de la publicidad, oralidad, contradicción e inmediación.

Sostiene la tesis opuesta la sentencia de la Audiencia Provincial de Huelva, Sección $1^{\mathrm{a}}$, de 5 de marzo de 2009, que permite, en primer lugar, que sea leída en el plenario la declaración de la víctima prestada durante la instrucción, pese a guardar silencio en el acto del juicio y, además, que dicha declaración sea valorada como prueba, a los efectos de dictar la sentencia que proceda en derecho. El Juzgado de lo Penal n. 2 de Huelva había dictado sentencia absolutoria, recurrida en apelación por la Fiscalía, por haberse impedido dar lectura a las declaraciones realizadas por la víctima en fase de instrucción después de acogerse a la dispensa del deber de declarar en la vista oral. La sentencia de la Audiencia considera que se está malinterpretando el sentido de la dispensa y que el derecho a no declarar, cuando se ejerce tardíamente en juicio, solo tiene efectos a partir del momento en el que se insta, sin que pueda

40 Vid. Miranda Estrampes, Manuel, "Particularidades de la prueba en los delitos de violencia de género”, op. cit., pp. 458 y 459; PELAYO LAVÍN, MARTA, “¿Es necesaria una reforma del art. 416 LECrim. para luchar contra la violencia de género?”, op. cit., p. 516; SibONY, RuBy et al., "La prueba y la dispensa del deber de declarar por la testigo-víctima en los procesos de violencia de género", op. cit., p. 20; sTs 10/02/2009. 
operar retroactivamente, ni alcanzar, por consiguiente, a la declaración anterior válidamente emitida ${ }^{41}$.

En nuestro estudio, en algo más de un $20 \%$ de los procesos concluidos con una sentencia absolutoria las víctimas se negaron a ratificar en el juicio oral lo ya depuesto en la fase de instrucción $(20,88 \%, n=38)$. Ese dato pone de manifiesto, nuevamente, la difícil situación en que se hallan las mujeres que sufren violencia cuando se ven en la tesitura de tener que declarar en juicio como testigos, especialmente cuando ellas mismas son la verdadera notitia criminis. Además, de acuerdo con nuestros datos, su actitud influyó de forma relevante (como factor estadísticamente significativo, p-valor $=0,0055$ ) en la decisión final: en un 44,18\% de los casos en que las mujeres hicieron uso de ese derecho el acusado fue exculpado, disminuyendo dicho porcentaje hasta el 29,15\% en el caso contrario (Tabla 5).

\section{Tabla 5}

\begin{tabular}{|c|c|c|c|c|c|}
\hline & \multicolumn{5}{|c|}{ La víctima ejerce el derecho a no declarar } \\
\hline & \multicolumn{2}{|c|}{$\mathrm{Si}(\mathrm{N}=\mathbf{8 6})$} & \multicolumn{2}{|c|}{ No $(\mathrm{N}=494)$} & \multirow[b]{2}{*}{ p-valor } \\
\hline & $\begin{array}{c}\text { Fr. } \\
\text { Absoluta }\end{array}$ & $\%$ & $\begin{array}{c}\text { Fr. } \\
\text { Absoluta }\end{array}$ & $\%$ & \\
\hline \multicolumn{6}{|l|}{ Fallo judicial } \\
\hline Absolución & 38 & $44,18 \%$ & 144 & $29,15 \%$ & \multirow[t]{2}{*}{0,0055} \\
\hline Condena & 48 & $55,81 \%$ & 350 & $70,85 \%$ & \\
\hline
\end{tabular}

Fuente: Expedientes obrantes en la Fiscalía de Área de Santiago de Compostela.

\section{COMPORTAMIENTOS PROCESALES DE LAS VÍCTIMAS Y PRUEBA INDICIARIA}

Los casos en que la fuente originaria de conocimiento de los hechos denunciados, en esta clase de procedimientos, proviene de alguien distinto de la propia víctima son escasos, poco representativos. Teniendo en cuenta ese dato, y a la vista de los comportamientos procesales de buena parte de las víctimas-testigos, parece esencial disponer, en el acto del juicio oral, de un cuadro indiciario lo suficientemente sólido como para permitir recurrir, en su caso, al método de la prueba indiciaria.

Ahora bien, y sin necesidad de traer a colación supuestos especialmente problemáticos (como los de denuncias de agresiones sexuales sufridas por menores o personas dependientes en el medio doméstico o de maltrato psicológico continuado), es preciso apuntar que la violencia de género es tan compleja en sus circunstancias y factores

41 Vid. en esa misma línea Herrero Yuste, Miguel, "Violencia de género y art. 416 de la Lecrim", La Ley Penal, n 24, Madrid, Wolters Kluwer, 2006, pp. 62 y ss. 
que la construcción de la prueba siempre aparecerá, a la fuerza, como una tarea interdisciplinar, en la que a la Medicina Legal le corresponde un rol muy significativo ${ }^{42}$.

El que con frecuencia se produzca en la intimidad del ámbito doméstico, la inexistencia de huellas visibles de la violencia psicológica, la incomparecencia de la víctima, la retractación de la denuncia por el temor a represalias y la dependencia psicológica y económica del agresor son factores que hablan, en efecto, en favor de la importancia de la prueba pericial o forense, cuyo sentido es el de reconstruir los hechos determinando de modo concluyente (y no por exclusión) el nexo causal ${ }^{43}$. Los factores clave en esa reconstrucción serán, entre otros, junto con la valoración de la lesión, la estimación de la compatibilidad entre las lesiones que se hayan podido comprobar y los mecanismos empleados para lesionar y la valoración de la situación emocional en que se halla la víctima después de los hechos, llevada a cabo por la asistencia sanitaria convencional cuando interviene para tratar las posibles lesiones físicas ${ }^{44}$. Además, y pensando fundamentalmente en la recreación del clima violento eventualmente objeto de denuncia, habrá de contarse con testimonios y datos periféricos (como el testimonio de vecinos o amigos o los daños causados en el domicilio) ${ }^{45}$.

En suma, debido a su ya aludida complejidad, y a que debe producirse en el marco de un procedimiento legal, es imprescindible que la prueba en los procesos por violencia de género se aborde con una perspectiva interdisciplinar y vertebrada. A la primera de las vertientes responde la creación del denominado equipo forense (Unidades de Valoración Integral), formado en principio por los propios médicos forenses, psicólogos y trabajadores sociales ${ }^{46}$. La segunda nota guarda relación, en cambio, con los

42 Vid. Serrat Moré, Dolores, "Violencia doméstica y de género: aspectos médico-legales", Derecho y Salud , n 38, Santiago de Compostela, Asociación de Juristas de la Salud, 1999, p. 44; CHINCHILlA BARICARTE, MARÍA José et al., "Construcción de los hechos desde la prueba en procedimientos de violencia doméstica”, op. cit., pp. 14 y 15; CoBo Plana, JuAn ANTONIO, "El juez y la prueba forense en la violencia de género", Cuadernos de Derecho Judicial, vol. IV, Madrid, Consejo General del Poder Judicial, 2006, p. 183.

43 Vid Asensi PÉREZ, LAura FÁtima, "La prueba pericial psicológica en asuntos de violencia de género", Revista Internauta de Práctica Jurídica, vol. 21, Valencia, Asociación de Juristas Valencianos, 2008, pp. 15 y ss.; Rodríguez CAlvo, María Sol / Luis CONCHEIRo CARRo. La violencia de género: aspectos médico-legales de la práctica clínica, en AA. VV. La violencia de género: aspectos médicolegales y jurídico-penales. Rodríguez Calvo, María Sol / FERnando VÁzQuez-Portomeñe SEIJAS (comps.), Valencia, Tirant lo Blanch, pp. 157 y ss.

44 Vid. Chinchilla Baricarte, María José et al., "Construcción de los hechos desde la prueba en procedimientos de violencia doméstica”, op. cit., pp. 14 y 15; CoBo Plana, JuAn Antonio, "El juez y la prueba forense en la violencia de género", op. cit., pp. 236 ss.; CASAS SÁncheZ, JuAn De Dios / MARÍA SOlEDAD RodríGuez AlbarRán, "Valoración médico-forense de la mujer maltratada", Revista Española de Medicina Legal, vol. 36, n. ${ }^{\circ}$ 3, Madrid, Elservier, 2010, pp. 112 y ss

45 Vid. Casas Sánchez, Juan de Dios / María Soledad Rodríguez Albarrán, "Valoración médicoforense de la mujer maltratada”, op. cit., p. 114.

46 García Minguito, Laura, Estudio médico-forense de la violencia de género: análisis de la calidad de los partes de lesiones, Madrid, Universidad Complutense de Madrid, 2010, p. 108; JuAN De Dios 
guiones o protocolos de trabajo diseñados al efecto, a modo de códigos de buenas prácticas. Su correcto seguimiento debería traducirse en la incorporación a todos los procedimientos de una serie de documentos, entre ellos, el parte de lesiones de comunicación al juzgado, el parte de asistencia inicial de lesiones o documento que contenga una descripción pormenorizada de las lesiones y la actuación asistencial efectuada ${ }^{47}$. Al margen de ello, también debe tratar de convencerse a las víctimas y familiares o allegados para que traigan todos los documentos que pudieran ser importantes para conocer las circunstancias y aspectos vinculados a los hechos, como los antecedentes documentados de otras agresiones a la misma persona o a otras personas del mismo medio doméstico. La aportación de todos estos materiales adquiere un especial protagonismo a la hora de ayudarle al juez a hacerse una idea de la violencia sufrida.

Obviamente, la correcta producción de la prueba pericial habrá de enfrentar un cúmulo de obstáculos, que van desde la propia dificultad para lograr la presencia de ese equipo forense interdisciplinar en los juicios rápidos (por las limitaciones a la hora de disponer de equipos y por la incompatibilidad entre la complejidad de la valoración pericial psicosocial y lo ajustado de los períodos de tiempo de los juicios rápidos), hasta su excesiva carga de trabajo, derivada del encadenamiento de valoraciones penales y civiles ${ }^{48}$. Todo ello sin perder de vista las dudas y reticencias manifestadas por no pocos profesionales a la hora de emitir el parte de lesiones y enfrentarse, en consecuencia, a conflictos médico-legales difíciles de solventar ${ }^{49}$.

\section{CONCLUSIÓN}

Este trabajo nos ha permitido corroborar que hay una serie de factores y variables que incentivan o refuerzan claramente la decisión de la víctima de no interponer denuncia (la convivencia en pareja con el agresor, la convivencia con familiares, el hecho de compartir el domicilio con los hijos y la titularidad en propiedad de la vivienda en la que la víctima convive con el agresor), así como la incidencia del testimonio

Casas Sánchez / María Soledad Rodríguez Albarrán, "Valoración médico-forense de la mujer maltratada", op. cit., pp. 111 y 112.

47 Vid. Serrat Moré, Dolores, "Violencia doméstica y de género: aspectos médico-legales", op. cit., p. 44; Cobo Plana, Juan Antonio, "El juez y la prueba forense en la violencia de género", op. cit., p. 236; GARCía Minguito, LAURA, Estudio médico-forense de la violencia de género: análisis de la calidad de los partes de lesiones, op. cit., pp. 96 y ss.

48 Vid. Cовo Plana, Juan Antonio, "El juez y la prueba forense en la violencia de género", op. cit., p. 185

49 Vid. Lorente Acosta, Miguel, "Violencia y maltrato de género (I). Aspectos generales desde la perspectiva sanitaria”, Emergencias, n. ${ }^{\circ}$ 20, Madrid, SANED, 2008, p. 196; GARCíA Minguito, LAURA, Estudio médico-forense de la violencia de género: análisis de la calidad de los partes de lesiones, op. cit., p. 94. 
de las propias víctimas en el desarrollo de los procesos por violencia contra la mujer. Así, hemos documentado que en algo más de una quinta parte de las sentencias absolutorias aquellas se habían negado a ratificar en el juicio oral lo ya depuesto en la fase de instrucción, "obligando" al órgano judicial a absolver por inexistencia de prueba de cargo "de entidad bastante".

Todo ello nos da pie para defender la necesidad de intensificar las estrategias de apoyo e intervención en el colectivo de víctimas que han decidido interponer denuncia. En este sentido, no nos parece descabellado otorgarle un tratamiento similar al que se dispensa a los menores, de forma que se permita la aplicación de modos de exploración forense en los que vengan asistidas por un psicólogo especialista de la unidad.

\section{BIBLIOGRAFÍA}

Armero Villalba, S. (2004). “Diligencias de prueba. Rectractación de las víctimas. La protección de la víctima en el curso del proceso", en Violencia física y psíquica en el ámbito familiar ( $1^{a}$ reunión de Fiscales encargados del Servicio de Violencia Familiar), Madrid: Centro de Estudios Jurídicos.

Albertín Carbó, P., Cubells Serra, J. y Calsamiglia Madurga, A. (2009). “Algunas propuestas psicosociales para abordar el tratamiento de la violencia hacia las mujeres en los contextos jurídico-penales”, en Anuario de psicología jurídica, Vol. 19.

ASENSi PÉREZ, L. F. (2008). "La prueba pericial psicológica en asuntos de violencia de género", en Revista Internauta de Pràctica Jurídica, Vol. 21.

BLAY GIL, E. (2014). "Voy o no voy": el recurso a la policía en el caso de la violencia de género. Perspectivas de las víctimas”, en Estudios Penales y Criminológicos, Vol. XXXIII.

B ARRIENTOS PACHO, J. M. (2010). "Denuncia y testimonio entre cónyuges o parientes sin advertencia previa de la dispensa legal. Validez y eficacia en juicio", en Diario La Ley, n. ${ }^{\circ} 4$.

Buzawa, E. S. y Buzawa, C. G. (2003). Domestic Violence. The Criminal Justice Response, Thousand Oaks, London, New Delhi: SAGE.

Calle Fernández, S. (2004). "Consideraciones sobre la victimización secundaria en la atención social a las víctimas de la violencia de género”, en Portularia, n. ${ }^{\circ} 4$.

Casas SÁnchez, J. D. D. y RodríGuez Albarrán, M. S. (2010). "Valoración médicoforense de la mujer maltratada", en Revista Española de Medicina Legal, Vol. 36. 
Chinchilla Baricarte, M, J., Gascón Sorribas, E. y Otero Gállego, M. (2001). "Construcción de los hechos desde la prueba en procedimientos de violencia doméstica”, en A. GARCÍA INDA y E. LOMBARDO (coord.), Terceras jornadas internacionales sobre Derechos y libertades fundamentales, Zaragoza: Mira.

Cobo Plana, J. A. (2006). "El juez y la prueba forense en la violencia de género", en Cuadernos de Derecho Judicial, Vol. IV.

Corcoy Bidasolo, M. (2010). "Ley y violencia de género. Problemática jurídicopenal y político-criminal de la regulación de la violencia de género y doméstica”, en InterseXiones, n. $^{\circ} 1$.

Douglas, H. (2012). "Battered women's experiences of the criminal justice system: Decentring the law", en Feminist Legal Studies, Vol. 20.

Fernández-Figares Molares, M. J. (2012). "La fuerza probatoria del testimonio de la víctima en la condena por delitos de violencia contra la mujer", en Revista Internauta de Práctica Jurídica, n. ${ }^{\circ} 28$.

Ferreiro BaAmonde, X. (2005). La víctima en el proceso penal, Madrid: La Ley.

Fuentes Soriano, O. (2009). El enjuiciamiento de la violencia de género, Madrid: Iustel.

García Minguito, L. (2010). Estudio médico-forense de la violencia de género: análisis de la calidad de los partes de lesiones, Madrid: Universidad Complutense.

Gudín Rodríguez-Magariños, F. (2009). "El silencio procesal de las víctimas: ¿caballo de troya para futuros maltratos?”, en Actualidad Jurídica Aranzadi, n. . 769.

Herrero Yuste, M. (2006). "Violencia de género y art. 416 de la LeCrim", en La Ley Penal, Vol. 24.

Hoyle, C. y Sanders, A. (2000). "Police Response to Domestic Violence", en The British Journal of Criminology, Vol. 40.

De Hoyos SAncho, M. (2008). "Nuevas tendencias en la investigación y prueba de los delitos de violencia doméstica y de género", en C.ArAngüEnA y A. SANZ Morán (coord.), La reforma de la justicia penal, Valladolid: Lex Nova.

LARRAURi PijoÁn, E. (2003). “¿Por qué retiran las mujeres maltratadas las denuncias?”, en Revista de Derecho Penal y Criminología, Vol. 12. 
LARRAuri PijoÁn, E. (2007). Criminología crítica y violencia de género, Madrid: Trotta.

Laurenzo Copello, P. (2008). "La violencia de género en el Derecho penal: un ejemplo de paternalismo punitivo", en P. LAUREnZo Copello, M. L. MAQUEDA ABreU y A. M. Rubio CAstro, Género, Violencia y derecho, Valencia: Tirant Lo Blanch.

Lorente Acosta, M. (2008). "Violencia y maltrato de género (I). Aspectos generales desde la perspectiva sanitaria", en Emergencias, Vol. 20.

Magro SerVet, Vicente (2005). "La imposibilidad de conceder a las víctimas de la violencia de género la dispensa de declarar contra sus agresores (artículo 416 LECrim): ¿Es necesaria una reforma legal?”, en La Ley, n 4.

Miranda Estrampes, M. (2009). "Particularidades de la prueba en los delitos de violencia de género", en M. DE Hoyos SANCHO (dir.), Tutela jurisdiccional frente a la violencia de género: aspectos procesales, civiles, penales y laborales, Valladolid: Lex Nova.

Medina, J. J. (2002). Violencia contra la mujer en la pareja. Investigación comparada y situación en España, Valencia: Tirant lo Blanch.

Olaizola Nogales, I. (2010). "Violencia de género: elementos de los tipos penales con mayor dificultad probatoria”, en Estudios penales y criminológicos, Vol. XXX.

Pelayo Lavín, M. (2009). “¿Es necesaria una reforma del art. 416 LeCrim. para luchar contra la violencia de género?”, en M. DE Hoyos SANCHO (dir.), Tutela jurisdiccional frente a la violencia de género: aspectos procesales, civiles, penales y laborales, Valladolid: Lex Nova.

PiÑEIRo Zabala, I. (2011). "La víctima de la violencia de género y la dispensa del artículo 416 de la LECrim”, en Revista Jurídica de Castilla León, n. 24.

Quintero Verdugo, M. I. (2011). "La realidad jurídico-social de los delitos de violencia de género", en Intervención psicoeducativa en la desadaptación social, n. ${ }^{\circ}$.

Rodríguez Calvo, M. S . y Concheiro Carro, L. (2013). "La violencia de género: aspectos médico-legales de la práctica clínica", en M. S. RodríGuez CALvo y F. VÁZQueZ-Portomeñe SEIJAS (ed.), La violencia de género: aspectos médico-legales y jurídico-penales, Valencia: Tirant lo Blanch.

RoIG MARZÁ, C. (2012) "La víctima como testigo en los procesos penales por violencia de género: especial referencia a la Jurisprudencia de la Comunidad Valenciana", en Revista del Instituto Universitario de Investigación en Criminología y Ciencias 
Penales de la Universidad de Valencia. Disponible en http://www.uv.es/recrim/recrim12/recrim12i01.pdf. Consultado el 29/8/2016.

Serrano Hoyo, G. (2010). "Sobre las posibles conductas procesales de la mujer víctima de delitos de violencia de género", en Anuario de la Facultad de Derecho de la Universidad de Extremadura, Vol. XXVIII.

SERrat Moré, D. (1999). "Violencia doméstica y de género: aspectos médicolegales", en Derecho y Salud, n. 38 .

Sibony, R., Serrano Ochoa, M. A. y Reina TARAnzo, O. (2011). "La prueba y la dispensa del deber de declarar por la testigo-víctima en los procesos de violencia de género", en La Toga, n. ${ }^{\circ} 182$.

Vives Cases, C., Torrubiano Domínguez, J. y Álvarez Cardet, C. (2008). “Distribución temporal de las denuncias y muertes por violencia de género en España en el período 1998-2006”, en Revista Española de Salud Pública, n. 82. 